\title{
Politik Islam di Malaysia; \\ Studi tentang Partai Al-Islam Se-Malaysia (PAS) di Kelantan
}

\author{
Syamruddin Nasution \\ Universitas Islam Negeri Sultan Syarif Kasim Riau \\ Email: syamruddinnst@yahoo.com \\ Abd. Ghofur \\ Universitas Islam Negeri Sultan Syarif Kasim Riau \\ Email: ghofur06@yahoo.com
}

\begin{abstract}
Kelantan is one of the 13 states in Malaysia, the struggle to implement Islamic law in Kelantan has been going on since the birth of PAS in 1951. However, the autonomy or authority in the implementation of Islamic law aspired by PAS has many obstacles because it is against the Federal Law and Court Act Syariah. The Federal Law does not adhere to the principles of the Islamic state and does not want the establishment of Islamic law as opposed to legal products in the state of Kelantan. Eventually the clash between the rules of the federal government and the state, forced state regulations to be repealed by the federal government. This article explains the various efforts in the application of Islamic law conducted by PAS in the executive, legislature and Syuro Council non-stop by continuing to perfect its legal products in the form of Kelantan Syariah Criminal Enactment 1993 on hudud law, Qishas and Tazir, as well as district regulations (perda) prohibits various disobedience.
\end{abstract}

Keywords: PAS, Islamic Law, Kelantan

\begin{abstract}
Abstrak: Kelantan merupakan salah satu dari 13 negara bagian di Malaysia, perjuangan penerapan syariat Islam di Kelantan telah berjalan sejak lahirnya PAS tahun 1951. Namun otonomi atau kewenangan dalam penerapan syariat Islam yang dicita-citakan oleh PAS mengalami banyak hambatan karena bertentangan dengan UU Federal dan Akta Mahkamah Syariah. Dalam UU Federal tidak menganut azas negara Islam dan tidak menginginkan tegaknya hukum Islam berseberangan produk hukum di negeri kelantan. Akhirnya perbenturan diantara aturan pemerintah federal dan negara bagian tersebut, menjadikan peraturan negara bagian terpaksa dibatalkan pemerintah ferderal. Tulisan ini menjelaskan berbagai Upaya-upaya dalam penerapan syariat Islam yang dilakukan PAS di eksekutif, legislatif dan Majlis Syuro yang tiada henti dengan terus menyempurnakan produk hukumnya baik dalam bentuk Enakmen Jenayah Syariah Kelantan 1993 tentang hukum budud, Qishas dan Tazir,serta peraturan-peraturan daerah (perda) melarang berbagai kemaksiatan.
\end{abstract}

Kata Kunci: PAS, Syariat Islam, Kelantan 


\section{PENDAHULUAN}

Sistem pemerintahan demokrasi telah dijadikan sebagai tatanan alternatif bernegara oleh sebagian besar negara di dunia ketimbang pilihan sistem pemerintahan monarchi absolut atau kerajaan apalagi sistem khilafah. Hal ini disebabkan demokrasi sebagai asas kenegaraan telah memberikan arah bagi peranan masyarakat yang lebih besar untuk menyelenggarakan negara sebagai organisasi tertingginya. Salah satu bentuk pemerintahan demokrasi yang memberikan peran yang lebih besar bagi masyarakat dalam proses penyelenggaraan negara adalah sistem otonomi atau desentralisasi. Sistem otonomi atau desentralisasi dimaknai sebagai upaya pelimpahan kewenangan dan tanggung jawab dari pemerintah pusat kepada pemerintah daerah, atau pemerintahan federasi kepada negara bagian.

Kelantan merupakan salah satu dari 13 negara bagian di Malaysia, Perkembangan Islam di Kelantan
Malaysia, memiliki hubungan yang erat dengan perkembangan Islam semenanjung Malaya masa awal hingga kini. Pasang surut penerapan syariat Islam di Kelantan tentunya berkaitan erat dengan kewenangan yang diberikan oleh pemerintah federal Kuala Lumpur kepada masing-masing negara bagian. Jika negara bagian Kelantan disimak dari sejarah perkembangan politiknya, sejatinya lebih di dominasi oleh partai Islam yaitu Partai Al-Islam Semalaysia (PAS). Sejak Malaysia merdeka tanggal 31 Agustus 1957 M hingga saat ini, PAS mampu menguasai pemerintahan negara bagian Kelantan, namun otonomi atau kewenangan dalam penerapan syariat Islam yang dicita-citakan oleh PAS sering mengalami banyak hambatan karena bertentangan dengan UU Federal. Dalam UU Federal tidak menganut azas negara Islam dan tidak menginginkan tegaknya hukum Islam berseberangan dengan Peraturan yang dikeluarkan oleh negara bagian kelantan. Akhirnya perbenturan 
diantara aturan pemerintah federal dan negara bagian tersebut, menjadikan peraturan negara bagian terpaksa dibatalkan pemerintah ferderal.

Partai al-Islam Se-Malaysia (PAS) lahir pada tanggal 23 Agustus 1951 bertepatan tanggal 21 Zulkaidah 1370 H di Kelab Melayu Banda Butterworth seberang Prai ${ }^{1}$. Partai ini lahir dipelopori oleh beberapa ulama dari perkumpulan United Malaya National Organization (UMNO), yang awalnya (1946-1948 M) hanya berbentuk organisasi kemasyarakatan bagi perkumpulan orang-orang Melayu. Namun pada pertengahan 1948 M, organisasi ini mengubah haluan perannya ke ranah politik. Dalam perpolitikan orang Melayu masa itu, ada dua kubu yang memiliki paham ideologi berbeda. Satu pihak berbasis pendidikan Barat, sementara di pihak lain memiliki basis pendidikan Timur Tengah. Kelompok Pertama membawa visi politik mengarah kepada demokrasi

1 Abdurrahman H Abdullah, Pemikiran Politik Islam di Malaysia, Sejarah dan Aliran (Jakarta: Gema Insani Press. 2007), 223.
Barat, yaitu memiliki konsep bahwa antara agama dan politik tidak mungkin dipadukan, mereka umumnya mendapat restu dan pengakuan dari pihak kolonial Inggris. Sementara kelompok Kedua, memandang politik sebagai bagian dari Islam, Karena itu Islam dianggap sebagai Din wa al Daulah. ${ }^{2}$ Oleh pihak Inggris kelompok terakhir ini dianggap sebagai oposisi pemerintah bentukannya.

PAS sebagai partai Islam yang berkuasa di satu-satunya negara Bagian Kelantan, pada awalnya lebih banyak mendapat dukungan dari kalangan ulama, guru-guru agama dan kalangan masyarakat petani, karena kelompok ini disinyalir masih tetap berpegang kuat dengan agama dan cita-cita luhur tegaknya syariat Islam dan hukum Islam di Malaysia. PAS dibangun di atas kehancuran partai Hizbul Muslimin (HAMIM), yaitu Partai Politik Islam pertama pada masa kolonial Inggris ada di Malaysia. Partai HAMIM ini

2 Ahmad Azam, Merdeka Dengan Perlembagaan (Penang: Pustaka Semenanjung, 1995), 38. 
digerakkan oleh kelompok muslim Melayu yang memiliki komitmen dengan tiga dasar perjuangan. Pertama, untuk membebaskan bangsa Melayu dan tanah Melayu dari penjajahan Inggris. kedua, membentuk negara Islam sejagat, dan Ketiga, untuk mewujudkan tanah Melayu sebagai negara "Daar alIslam". ${ }^{3}$

Ada beberapa kalangan pakar meragukan kemampuan PAS dalam memperjuangkan politik Islam yang dicita-citakan. Candra Muzaffar misalnya menilai bahwa PAS tidak secara jelas mengemukakan tentang bentuk struktur pemerintahan Islam yang dijalankan ketika mereka suatu saat mampu memerintah. Kemudian terkait distribusi kekuasaan antara Badan legislatif, yudikatif dan eksekutif dalam pemerintahan Islam yang diperjuangakan PAS juga belum jelas diuraikan secara detil, apakah disatukan atau dipisah diantara ketiga lembaga yang digagas oleh

3 Ahmad Azam, Merdeka dengan Perlembagaan, 38.
JJ.Resseou dengan Trias Politika. ${ }^{4}$ Kritik yang hampir senanda juga lahir dari Prof Sayyed Husein alAttas, menurutnya untuk menegakkan negara Islam, dibutuhkan hakim-hakim Islam yang memahami perundang-undangan Islam. Dan jika mengusung negara Islam yang menjadi simbol, sementara dalam pelaksanaanya tidak mencerminkan Islam yang benar, maka ia hanya akan mencemarkan agama Islam dan menjadi citra yang lebih buruk lagi. ${ }^{5}$

Dari uraian di atas menarik untuk ditela'ah lebih mendalam dalam bentuk penelitian tentang Peranan Partai Al-Islam Se-Malaysia (PAS) di Kelantan dalam menerapkan Syariat Islam. Adapun tujuan penelitan ini pertama, adalah untuk mengkaji lebih mendalam pandangan politik Islam PAS di Kelantan Malaysia. Kedua, untuk menelaah Penerapan Syariat Islam, bentuk-

4 Candra Muzaffar, Islamic Resurgence In Malaysia, (Petaling Jaya : Fajar Bakti. 1987), 59-60.

5 Ibrahim Ahmad, Konflik UMNO PAS dalam Isu Islamisasi, (Selangor : IBS Printed, 2003), 97. 
bentuk peraturan daerah (Perda) Syari' dan kendalanya di Negeri Kelantan Malaysia.

\section{METODE PENELITIAN}

Metode kajian dalam penelitian ini menggunakan tela'ah kepustakaan (library research). Kajian literatur ini diambil dari beberapa sumber yang membahas tema di atas, seperti Pemikiran Politik Islam di Malaysia, Sejarah dan Aliran (Jakarta : Gema Insani Press. 2007) 6; Merdeka Dengan Perlembagaan (Penang : $\begin{array}{lll}\text { Pustaka Semenanjung, 1995), } & 7\end{array}$ Ibrahim Ahmad, Konflik UMNO PAS dalam Isu Islamisasi, (Selangor : IBS Printed, 2003), dan Nakha'ie Haji Ahmad, Konsep Negara Islam dan Matlamatnya, (Kuala Lumpur: Syarikat Al-Muslimah, 2004) ${ }^{8}$ Islamic Resurgence In Malaysia, (Petaling Jaya: Fajar Bakti. 1987); Perlembagaan

${ }^{6}$ Abdurrahman $\mathrm{H}$ Abdullah, Pemikiran Politik Islam di Malaysia, Sejarah dan Aliran (Jakarta: Gema Insani Press. 2007), 72

7 Ahmad Azam, Merdeka Dengan Perlembagaan (Penang: Pustaka Semenanjung, 1995), 20.

${ }^{8}$ Nakha'ie Haji Ahmad, Konsep Negara Islam dan Matlamatnya, (Kuala Lumpur: Syarikat Al-Muslimah, 2004), 24.
Persekutuan, (Selangor: Law Book Services, 2009). dan sumber lain yang mendukung. Teknik Pengumpulan data dalam penelitian ini dimulai dari akumulasi data verifikasi data, interpretasi data dan dilanjutkan dengan penulisan. $^{9} \quad$ Data dikelompokkan menjadi dua jenis yaitu data primer dan sekunder.

Jika dilihat dari segi subjek penelitian, maka penelitian ini masuk penelitian sejarah dan sejarah sosial politik keagamaan, sebab subjek penelitian sejarah itu adalah sosial, politik, keagamaan, ekonomi dan gejala alam. ${ }^{10}$ Data-data yang terkumpul baik dari data primer maupun data sekunder selanjutnya dilakukan analisis. Setelah semua kegiatan pengkajian data dan analisis data selesai dilanjutkan dengan penyempurnaan laporan penelitian. Teknik analisis menggunakan pendekatan analisis sosio-historis dan Content analisis. Analisis data

${ }^{9}$ John Funston (Edt.), Government and Politicsin Southest Asia (Singapure: ISEAS, 2001), 11.

10 Dudung Abdurrahman, Metode Penelitian Sejarah (Jakarta: Wacana Ilmu, 1999), 7. 
dilakukan dengan menggunakan langkah-langkah diantaranya pertama, deskriptif, yaitu untuk mendapatkan gambaran umum yang meliputi; Islam di Kelantan; Peranan PAS di Kelantan dan bentuk-bentuk Peraturan untuk penerapan syariat Islam dan kendala-kendala yang dihadapi. Kedua, Interpretatif, yaitu peneliti akan menyelami dan menelaah sumber-sumber data yang diperoleh agar mendapatkan tafsirantafsiran yang lebih faktual dan signifikan. Pendekatan penelitian dengan analisis kritis (critical analysis), metode ini dipergunakan untuk menganalisis data-data yang telah diinterpretasikan dan dikritisi sehingga ditemukan suatu kesimpulan yang lebih komprehensif.

\section{PEMBAHASAN}

\section{A. Profil Islam di Kelantan Malaysia}

Negeri bagian Kelantan merupakan salah satu dari 13 negara bagian yang ada meliputi (1) Johor, (2) Kedah, (3) Kelantan, (4) Melaka, (5) Negeri Sembilan, (6) Pahang, (7)
Perak, (8) Perlis, (9) Pulau Pinang, (10) Kelantan, (11) Sarawak, (12) Selangor, dan (13) Trengganu. Selain itu terdapat teritorial federal yaitu (Wilayah Persekutuan) yang mencakup tiga wilayah yaitu (1) Ibukota Kuala Lumpur, (2) Labuan, dan (3) Putrajaya. Dan hingga saat ini masih ada sembilan negara bagian yang melanjutkan tradisi kesultanan Islam di Semenanjung Melaya meliputi negeri Sembilan, Perlis, Johor, Kedah, Kelantan, Perak dan Trengganu..

Negara Bagian Kelantan luasnya sekitar $14.922 \mathrm{Km} 2$ dan dihuni sejumlah 1,678,001 jiwa berdasarkan Sensus 2010. Sebelumnya terdapat sensus penduduk tahun 2000 berjumlah 1,313,014 jiwa. Negara bagian Kelantan meliputi 10 daerah (Kabupaten) yaitu: 1. Gua Musang; 2. Bachok; 3. Jeli; 4. Kota Bharu; 5. Kuala Kerai; 6. Machang; 7. Pasir Mas; 8. Pasir Puteh; 9. Tanah Merah dan 10. Tumpat. Kelantan, secara resmi di sebut dengan Negeri Kelantan Darul Naim merupakan salah satu negara bagian di Malaysia yang kaya dengan 
sumber alam. Ibukotanya terletak di

Kota Bharu, di timur laut Semenanjung Malaysia, yang berhadapan dengan Laut China Selatan, dan berbatasan dengan Thailand.

Dilihat dari aspek sosialbudaya, Kelantan merupakan negeri yang berbatasan dengan wilayahwilayah selatan Thailand yang dulu dikenal sebagai kesultanan Patani Darul Salam. Dan dari aspek sejarahnya, Kelantan mempunyai hubungan kekerabatan dengan Kesultanan Melayu Patani di Thailand Selatan seperti yang tersebar kini di propinsi Patani; Yala; Narathiwat; Satun dan Songkhla. Hubungan kekerabatan Kesultanan Melayu Kelantan mempunyai pertalian darah dengan Kesultanan Melayu Patani dan juga Kesultanan Melayu Negeri Champa (Kamboja). Setelah Kesultanan Melayu Patani dikhianati oleh kerajaan Budha Siam dengan dalih Integrasi maka sejak tahun $1902^{11}$ Raja kerajaan Siam,

11 John Funston, Malay Politic in Malaysia: A case study the UMNO and PAS
Chulalonkorn

menaklukkan

kesultanan Patani tahun 1902.

Akhirnya kesultanan Pattani telah dipecah menjadi beberapa wilayah kecil yang terdiri dari Yalla, Narathiwat, Patani, Satun dan Songkla dan sejak tahun 1902 M, wilayah itu telah berstatus menjadi negeri-negeri Bagian (propinsi) di Thailand Selatan.

Sedangkan memasuki tahun 1948 M, berdasarkan perjanjian Inggris dengan kerajaan Siam, Status pemerintahan selatan Thailand telah dipisahkan oleh Inggris, yaitu Kelantan di bawah negeri Persekutuan Malaysia jajahan Inggris dan negeri-negeri Pattani di bawah daerah taklukan kerajaan Siam (Thailand). Pada sisi sosio-budaya Kelantan mempunyai budaya yang unik berkaitan erat dengan tradisi dan budaya Negeri-negeri bekas kesultanan Patani. Asimilasi (perpaduan) antara budaya Melayu, Siam dan Islam menyisakan warisan budaya hingga kini terdapat dalam

(Kuala Lumpur: Dinamika Kreatif SDN BHD, 1997), 188. 
permainan rakyat seperti dzikir Barat, main Puteri, Mak Yong; menora dan lainnya. Mak Yong adalah drama, tarian, nyanyian, dan unsur-unsur komedi yang bercerita tentang dewa-dewi yang disampaikan melalui mulut, hanya menggunakan ingatan tanpa dialog tertulis ; sementara dzikir barat tradisi budaya yang dipengaruhi oleh unsur-unsur Islam. Sedangkan permainan rakyat Main Puteri dipengaruhi oleh unsur-unsur budaya Hindu. Sedangkan Menora merupakan dramatari masyarakat Siam yang berkembang dalam kalangan masyarakat Siam di Segenting Kra, yaitu di wilayah Pitchaburi, Surat Thani, Phatthalung, Nakhon Sithammarat dan Kelantan serta Kedah.

Kelantan sejak tahun 1511 M, sebenarnya sangat erat dengan penerapan syariat Islam. Menurut DR. Fadli, pada abad ke $16 \mathrm{M}$ Malaysia, termasuk Kelantan, diperintah raja-raja yang konsisten menjalankan syariat Islam. Bukti sejarah ini bisa dilihat dengan adanya
Undang-Undang yang berdasarkan syariat Islam, seperti UU pidana, muamalah, dan UU negara. Tapi, pada masa jajahan kolonial Inggris, syariat Islam di Malaysia, khususnya di Kelantan mengalami tekanan dan pelarangan karena bertentangan dengan kebijakan politik kolonial Inggris. Strategi penaklukan Inggris awalnya melalui misi perdagangan. Mereka melakukan jual beli dengan baik tetapi upaya-upaya monopoli perdagangan dan penjajahan semakin gencar dilakukan untuk meraup untung yang lebih besar.

\section{Kedatangan Inggris} memonopoli perdagangan ekonomi, lalu kemudian mulai menjajah syariat Islam dalam arti membatasi ruang gerak tokoh-tokoh muslim. Inggris mengubah cara pandang hidup (weltanshaung) syariat Islam di Malaysia dan Kelantan terpisah dengan urusan politik atau dikenal dengan sekularisasi, pemisahan antara agama dan negara. Negara dikelola dengan sIstem hukum kolonial. Kolonial Inggris bersedia memberikan kemerdekaan asal 
syariat Islam tidak dipakai sebagai konstitusi, sampai pada akhirnya HAMIM (Hizbul Muslimin) pun dibubarkan. Karena itu melayu terpecah menjadi dua kelompok: yaitu nasionalis Islam dan Nasionalis sekuler ${ }^{12}$ Usaha-usaha memberlakukan syariat Islam di Kelantan dilakukan sejak lahirnya PAS tahun 1951 hingga kini oleh kelompok nasionalis Islam.

\section{B. Negara Islam dalam Pandangan PAS}

Istilah negara dalam kajian ilmu politik mengandung banyak sekali pengertian. Salah satu makna terminologi negara dikemukakan oleh Roger F. Soltau bahwa "The State is an agency or authority managing or controlling these (common) affairs on behalf of and in the name of the community"13. Maksudnya negara adalah alat (agency) atau wewenang (authority) untuk mengatur atau mengendalikan persoalan-persoalan bersama atas nama masyarakat.

12Ahmad Azam, Merdeka Dengan Perlembagaan (Penang: Pustaka Semenanjung, 1995), 38.

13 Roger F. Soltau, An Introduction to Politics, London: Longmans, 1982), 1.
Dalam terminologi tersebut ada beberapa aspek yag tercakup dalam negara diantaranya : -memaksa, artinya agar undang-undang yang diterapkan pemerintah untuk mengatur masyarakat dapat dilaksanakan, terutama apabila sebagian masyarakat yang menentang undang-undang tersebut (anarkhi), dan hal ini perlu ada tindakan tegas dari pemerintah; ada pula unsur all encompasing, artinya undang-undang yang akan diterapkan mencakup semua orang tanpa kecuali, yaitu tidak mengenal perbedaan suku, ras, keturunan dan agama.

Dalam memahami hubungan antara Islam dan negara, terdapat tiga teori yang menarik untuk dimunculkan sebagaimana dikemukakan pemikir muslim Munawir $\quad$ Syadzali. ${ }^{14} \quad$ Ia mengelompokkan hubungan ini menjadi tiga aliran yang memiliki pandangan berbeda-beda satu

14 Munawir Syadzali, Islam dan Tata Negara: Ajaran, Sejarah dan Pemikiran, (Jakarta: Universitas Indonesia Press, 2004), 1-2. 
dengan lainnya. Pertama, Islam dianggap tidak semata-mata dalam pengertian Barat, yakni hanya menyangkut hubungan manusia dengan Tuhan. Sebaliknya Islam adalah agama yang sempurna untuk segala aspek kehidupan manusia, termasuk dalam urusan negara. Tokoh-tokoh aliran ini antara lain Hasan al-Banna, Sayyid Kuttub, dan Abu al'Ala Al-Maududi. Kedua, Islam dipandang sebagai agama dalam pengertian Barat yang tidak ada hubungannya dengan urusan kenegaraan. Nabi Muhammad dipandang sebagai seorang rasul biasa, seperti rasul lainnya, tidak pernah dimaksudkan untuk mendirikan dan mengepalai satu negara. Tokoh aliran ini antara lain Ali Abdul Raziq; dan Thaha Husein.

Kemudian aliran ketiga menolak pandangan bahwa Islam adalah suatu agama yang serba lengkap, termasuk di dalamnya memiliki sistem kenegaraan, tetapi aliran ini juga menolak anggapan bahwa Islam dalam pengertian Barat, yang hanya mengatur hubungan antara manusia dengan Tuhan. Kelompok ini berpendirian bahwa dalam Islam tidak terdapat sistem kenegaraan, tetapi terdapat seperangkat tata nilai etika bagi kehidupan bernegara, lingkup sosial, ekonomi dan lainya. Tokoh aliran ini antara lain Mohd. Husei Haikal, Komaruddin Khan dan Muhammad Imarah. 15

$$
\text { Partai Al-Islam se-Malaysia }
$$
(PAS) dalam hubungannya dengan tiga teori tersebut dapat dikelompokkan pada pemahaman aliran pertama, yaitu Islam dianggap bukan semata-mata dalam pengertian Barat yang memisahkan antara agama dan negara, karena agama hanya menyangkut urusan manusia dengan Tuhannya. Sebaliknya Islam dalam aliran pertama ini sejalan dengan pemikiran PAS yaitu agama yang sempurna dan lengkap mencakup semua aspek kehidupan manusia termasuk di dalamnya mengurusi masalah kenegaraan. Berkaitan dengan teori ini, PAS dalam beberapa pembahasan

15 Munawir Syadzali, Islam dan Tata Negara: Ajaran, Sejarah dan Pemikiran, 1-2. 
mengacu kepada teori politik Abu alA'la Al-Maududi yang mengargumentasikan bahwa negara merupakan bagian integral dari Islam. Lebih lanjut Menurut AlMaududi Islam memiliki konsep negara dan pemerintahan tersendiri yang lengkap. ${ }^{16}$ Selain itu Javid Iqbal juga berpendapat bahwa para faqih tradisional mensyaratkan tiga ciri penting suatu negara Islam yaitu Adanya masyarakat Muslim (Ummah); berlakunya syariat Islam; dan kedaulatan tertinggi ada di tangan Allah. ${ }^{17}$

Dalam pandangan PAS istilah negara dikemukakan oleh tokoh PAS, Abdul Hadi Awang, menurutnya suatu negara harus mendaulatkan hukum Allah; Syariat Allah wajib menjadi aqidah negara dan pegangan pemerintah. Karena dari aqidah

16 Pemikiran Al-Maududi tersebut lebih lengkap dalam karyanya, The Islamic Law and Constitution, Translated and edited bu Khursid Ahmad, (Lahore : Islamic Publikation, 1977). Lihat juga kritik Munawir Syadzali terhadap teori politik Al-Maududi dalam Munawir Syadzali, Islam dan Tata Negara: Ajaran, Sejarah dan Pemikiran, 157-159.

17 Mumtadz Ahmad (Ed), State, Politics and Islam (terj), Bandung: Mizan, 1986), 68. inilah maka Negara Islam mampu menegakkan konstitusi dan sistem kenegaraanya. ${ }^{18}$ Lebih lanjut menurut Hadi Awang Umat Islam wajib mendukung kedaulatan syariat Islam dan pemerintahan Islam punya komitmen untuk melindungi rakyat. Pemikiran tokoh PAS lain Nakhaie H. Ahmad mempertegas prinsip-prinsip negara Islam yang menjadi prasarat terwujudnya kemaslahatan umat; terciptanya keadilan dan kesejahteraan masyarakat. Prinsipprinsip tersebut dikemukakan secara rinci yaitu: negara dan pemerintahan Islam dibentuk atas dasar kedaulatan hukum Allah; negara dan pemerintahan Islam ditegakkan atas dasar kekuasaan ummah dengan pengertian bahwa negara Islam tidak akan terwujud tanpa dukungan umat; negara dan pemerintahan Islam ditegakkan atas dasar keadilan, karena keadilan merupakan prinsip penting negara Islam untuk kesejahteraan rakyat; negara Islam ditegakkan atas dasar sistem syura;

18 Hadi Awang, Konsep Negara Islam dan Matlamatnya, (Kuala Lumpur: Syarikat Al-Muslimah, 1996 ), 3. 
dan dalam negara Islam pemerintahannya bertanggungjawab penuh sedangkan rakyatnya wajib loyal dan patuh. ${ }^{19}$

Pandangan tentang negara Islam sebagaimana dijelaskan oleh tokoh PAS di atas terdapat kesesuaian dengan pandangan AlMaududi tentang negara Islam bahwa kedaulatan tertinggi dalam negara ada di tangan Tuhan; syariat Islam harus menjadi dasar negara; menghapus segala macam UndangUndang negara yang bertentangan dengan syariat Islam; dan pemerintah harus menggunakan kekuasaan sesuai dengan batas-batas yang ditetapkan dalam syariat Islam.

Dari prinsip-prinsip dasar Negara Islam tersebut, dapat dipahami bahwa salah satu cirinya menurut tokoh-tokoh PAS adalah (1) Syariat Islam harus ditegakkan dan dipatuhi, karena menurut mereka syariat Islam mampu memenuhi kebutuhan semua manusia di muka bumi ini sampai kapan pun.

19 Nakhaie H. Ahmad, Penghayatan Politik Islam dalam Pemerintahan, (Kuala Lumour : GG, Edar 1998), 30-37.
Tegaknya syariat Islam menurut Hadi Awang memiliki beberapa syarat Pertama, beriman kepada Allah, karena keimanan inilah yang akan menjadi tolak ukur ketundukan dan kepatuhan manusia secara ikhlas untuk menegakkan hukum Allah. Kedua, Universalisme hukum Islam, maksudnya adalah hukum Islam itu sejatinya akan menjadi rahmat bagi semesta alam, bukan hanya untuk satu suku, bangsa dan satu kawasan, tetapi untuk seluruh makhluk di bumi. Konsep kedua ini pada dasarnya bertentangan dengan paham nasionalisme yang pada awalnya berkembang di Barat. Ketiga, keadilan absolut. Maksudnya Islam mewujudkan persaudaraan sesama manusia dan memelihara kebebasan beragama meskipun tetap menyatakan bahwa Islam adalah satu-satunya agama yang benar, disamping itu juga untuk memelihara akal, jiwa, akhlak dan keturunan. ${ }^{20}$ Pandangan tersebut dapat dimaknai bahwa dengan ditegakkannya

20 Hadi Awang, Konsep Negara Islam dan Matlamatnya..., 9-12. 
syaraiat Islam, maka suatu Negara baru akan mampu menegakka hukum dan perunadang-undangan serta perangkat sistemnya secara totalitas. syariat Islam juga harus ditempatkan pada kedudukan yang tinggi, dengan begitu maka pelaksanaanya dapat terwujud dari berbagai aspek.

Selanjutnya ke (2) Negara Islam harus mendapat dukungan yang kuat dari rakyat atau kelompok yang menginginkan ditegakkan sistem pemerintahan Islam. Syarat-syarat dari ciri negara Islam ini adalah, pertama, sekelompok umat tersebut bertekad bulat untuk al-amr bi alma'ruf wan-nahyu 'an al-munkar, yaitu umat dengan ikhlas dan bertanggung jawab menyeru pada kebaikan dan mencegah segala kemunkaran. Kedua, beriman kepada Allah, yaitu iman yang dibina dengan dasar tauhid yang kokoh; ketiga, ummatan waahidah, maksudnya kelompok ini menerima konsep kesatuan umat, karena manusia pada dasarnya satu yaitu sama-sama makhluk Allah SWT.
Bila ditelaah dari sifat negara Islam, maka pendapat Hadi Awang di atas bahwa pemerintahan Islam mesti dikendalikan oleh orang-orang yang memiliki komitmen yang besar terhadap Islam seperti adil, jujur; saleh; berilmu dan berakhlak mulia. Hal tersebut agar terhindar dari kepemimpinan yang cenderung mengikuti hawa nafsu dan bertindak sewenang-wenang. Dalam kaitan inilah maka menurut tokoh-tokoh PAS perlu ditegakkan pemerintahan Islam sebagai corak khas, karena dengan berdirinya negara Islam akan mampu mengendalikan, pertama, tegaknya perintah shalat, yang di dalamnya terkandung hikmah jalinan komunikasi yang intens antara sesama manusia dengan Allah sang khalik. Kedua, ditegakkannya perintah zakat, agar distribusi perekonomian dalam Islam dapat berjalan lancar dan akan melahirkan kesejahteraan dan rasa keadilan. Dan ketiga, mampu menyeru yang ma'ruf dan mencegah yang munkar.

Peran PAS dalam aktivitas sosio-politik membentuk sekolompok 
massa yang mendukung cita-cita Islam dan terwujudnya pemerintahan Islam. Dambaan PAS akan pemerintahan Islam menurut Hadi Awang, merupakan hidayah Allah, karena dengan pertolongan Allah pemerintah akan mampu menggerakan negara sesuai dengan tujuan awal. Sebaliknya pemerintahan yang didasarkan pada jibayah, maka pemerintahan tersebut hanya bertujuan mengejar kesenangan dunia dan materi. Kritik PAS terhadap pemerintahan berkuasa UMNO Malaysia di mana tujuannya masih pada level jibayah. Apalagi dalam pandangan PAS, pemerintah berkuasa UMNO masih mempertahankan konstitusi Negara (Rukun Negara) menempatkan kedudukan tertinggi dengan mengabaikan dasar Al-Quran dan Sunnah Rasul. UMNO dalam menjalankan pemerintahan masih mendasarkan Undang-Undang Persekutuan (Perlembagaan Persekutuan) yang didasarkan dari warisan UU kolonial Inggris. ${ }^{21}$

21 Ibnu Hasyim, Konflik UMNO dan
Tanpa berdirinya negara Islam, menurut PAS syariat Islam akan sulit ditegakkan di tengah masyarakat, karena itu menurut PAS Negara Islam wajib didirikan. Hal ini juga pernah didialogkan antara pimpinan PAS dengan ulama terkenal Yusuf Qardawi. Dalam dialog tersebut tokoh-tokoh PAS kembali menegaskan bahwa pemerintahan berdasarkan hukum Islam adalah suatu kewajiban. Tidak ada pilihan lain dalam keputusan tersebut. Sebuah pemerintahan Islam yang berdasarkan Islam adalah pemerinthan yang melaksanakan hukum Islam. Konsep hidup seorang muslim menurut PAS dalam kaitan ini adalah kami dengar dan kami taati Allah SWT.22

\section{Sistem Pemerintahan Menurut PAS}

Pembahasan ini dimaksudkan untuk menelaah secara detil bentuk

PAS: Penyelesaian Menurut Islam (Kuala Lumpur: GG Edar, 2000), 59-60.

22 Lihat wawancara Yunus Said dengan Prof. DR. Yusuf Qardawi dalam Berita Harian, 28 Maret 1985, hlm. 10. 
pemerintahan yang dirancang PAS, pemilihan kepala Negara, wewenang dan pembagian kekuasaan serta partisipasi wanita muslim PAS dalam praktek politik.

Dalam perlembagaan PAS (Anggaran Dasar $=\mathrm{AD})$, bentuk Negara yang dicita-citakan PAS adalah sistem pemerintahan teokrasi (Kedaulatan Tuhan). Istilah Teokrasi dimaknai bahwa kekuasaan Tuhan berada di tangan umat Islam (pemimpin muslim) yang melaksanakannya sesuai dengan yang terkandung dalam al-Qur'an dan sunnah. Ide pemikiran tersebut dapat ditelusuri dari pemikiran tokoh PAS Hadi Awang yang menyatakan bahwa syariat Islam harus menjadi dasar aqidah Negara; hukum dan perundang-undangan Negara dan semua sistem yang terkait di dalamnya. Ia juga berpendapat negara Islam adalah negara yang mendaulatkan hukum Allah'23. Pernyataan ini menunjuk bahwa sumber kekuasaan datangnya dari

23 Hadi Awang, Konsep Negara Islam, hlm. 9 dan 20
Allah, sedangkan kepala Negara hanya sebatas pelaksana jalannya hukum Allah yang diwajibkan pada manusia.

Hadi Awang sejalan dengan PAS dalam Perelmbagaanya (AD) yang diterbitkan tahun 1977 dan tahun 1987. Tujuan berdirinya PAS dalam perlembagaan tersebut adalah "memperjuangkan terwujudnya dalam Negara Malaysia sebuah masyarakat dan pemerintahan yang terlaksana di dalamnya nilai-nilai Islam dan hukum Islam demi mendapatkan ridha Allah SWT".24 Alasan PAS bertekad mendirikan negara Islam dengan sistem teokrasi ini didasarkan bahwa semua muslim wajib tunduk pada syariat Allah (Undang-undang Allah). Hal ini mengingat bahwa semua manusia tanpa mengenal suku, bangsa dan warna kulit adalah sama-sama hamba Allah. Dan PAS menginginkan dasar Negara Islam adalah al-Quran dan Sunnah sebagai panduan dalam pemerintahan dan

24 Menteri Pendaftar Pertubuhan Malaysia, Perelmbagaan Partai Al-Islam SeMalaysia (PAS), pada pasal 5 ayat 1. 
dalam segala aspek kehidupan masyarakat.

Ada kesamaan antara bentuk pemerintahan yang dicita-citakan PAS dengan bentuk pemerintahan yang digagas oleh Al-Maududi. Pada prinsipnya Al-Maududi menginginkan pemerintahan Islam itu teokrasi. Namun sistem pemerintahan teokrasi ini perlu didukung oleh demokrasi sebagai jalan keluar terhadap masalah yang akan timbul dari kelompokkelompok elit yang akan memerintah dan mengurus Negara. Menurut AlMaududi sistem teokrasi dimaknai bahwa kekuasaan Tuhan berada di tangan umat Islam (pemimpin muslim) yang melaksanakannya sesuai dengan yang terkandung dalam al-Qur'an dan sunnah. Dalam sistem ini, umat Islam memiliki kedaulatan yang terbatas. Munawir Syadzali menamakan teori yang dikembangkan oleh al-Maududi tersebut dengan bentuk pemerintahan teo-demokrasi. ${ }^{25}$
Meskipun secara implisit ia juga menggunakan istilah Negara teokrasi yang demokratis.

Sistem pemerintahan teokrasi yang demokratis menurut pemikiran al-Maududi adalah sebagai " $A$ divine democratic government and the entire muslim population runs the state in accordance with the book of God and the practice of His Prophet". ${ }^{26}$ Al-Maududi menginginkan sistem pemerintahan teokrasi atau kedaulatan Tuhan yang demokratis dan semua penduduk berperan dalam pemerintahan dengan berpegang teguh pada alQuran dan Sunnah. Tujuan diadakan sistem teo-demokrasi ini menurut alMaududi adalah untuk menghindari terjadinya eksploitasi antar kelompok dalam masyarakat; memelihara kebebasan berpolitik; agama; ekonomi; pendidikan; menegakkan sistem keadilan sosial sesuai dengan al-Quran dan sunnah; memberantas kemungkaran serta mengayomi dan
25 Munawrir Sjadzali, Islam dan Tata Negara, 64 .
26 Abu al-'Ala al-Maududi, Political Theori of Islam,, 64. 
menjamin keamanan semua warga bangsa. ${ }^{27}$

Sistem teokrasi yang dicitacitakan Al-Maududi tidaklah sama dengan sistem teokrasi yang pernah berkembang di Barat. Karena sistem teokrasi Barat yang pernah diterapkan itu penuh dengan pengalaman pahit. Sistem ini di Barat cenderung diterapkan secara tiranis dengan membolehkan kelompok pris (pendeta) memonopoli pemerintahan Negara. Mereka beranggapan bahwa pemilik kitab ajaran agama (pendeta Kristen) yang mampu dan memahaminya adalah mereka yang berhak memerintah dan menjadi wakil Tuhan di bumi dan menguasai Negara. Lebih lanjut Al-Maududi menjelaskan : "A more apt name for Islamic policy would be the Kingdom of God which is describe in English as a Theocracy. But Islamic Theocracy is something altogether different...The theocracy built up by Islam is not rule by any particular religious class but by the

27 Amin Rais "Kata Pengantar" dalam buku Abul a'la Al-Maududi, Khilafah dan kerajaan, terjemahan, (Bandung: Mizan, 1993), 31. whole community of muslim including the ranke and file". ${ }^{28}$

Pemerintahan Islam menurut Al-Maududi lebih tepatnya disebut teokrasi yang berbeda sama sekali dengan model Barat, karena memiliki dasar yang berbeda antara keduanya. Dalam pemerintahan Islam menurut al-Maududi semua umat Islam wajib berpartisipasi tidak hanya dari kelompok kelas tertentu seperti bangsawan, agamawan dan lainnya, tetapi semua muslim dari kalangan atas hingga bawah. Karena dalam pemerintahan ini dikenal juga dengan pemerintahan langsung (direct democracy). ${ }^{29}$ Namun demokrasi ini tidak diterapkan di Negara Pakistan di mana saat itu AlMaududi bermukim, sedangkan di Indonesia sejak tahun 2004 telah mengamandemen UUD dengan

28 Abul 'Ala al-Maududi, Political Theory of Islam, op.cit., hlm. 65.

29 Sistem demokrasi langsung (direct democracy) pertama kali dikembangkan di Negara kota (city State) Yunani kuno abad ke 6-3 SM. Dalam system ini hak unuk membuat Keputusan politik dijalankan secara langsung oleh seluruh warga berdasarkan suara mayoritas. Miriam Budiarjo, Dasar-Dasar Ilmu Politik, (Jakarta : Gramedia, 2014), 53. 
sistem pemilihan presiden secara langsung tidak lagi melalui wakilwakil rakyat.

Sinergi PAS dan pemerintah dalam menerapkan syariat Islam di Kelantan dalam prakteknya harus menyesuaikan diri dengan UU pemerintahan federal Kuala Lumpur dengan tidak menjalankan demokrasi langsung, tetapi menggunakan demokrasi berdasarkan perwakilan (representative democracy). Alasan PAS menggunakan model ini karena didasarkan pada fakta sejarah politik Islam masa khulafa'al-Rasyidin (Khalifah Abu Bakar; Umar; Usman dan Ali) ketika itu tidak ada bukti yang menunjukan adanya keterlibatan semua umat Islam ikut memilih khalifah, termasuk dalam urusan pemerintahan. Urusan poltik dan pemerintahan saat itu hanya dikendalikan oleh sekelompok elit umat Islam yaitu para sahabat senior Rasulullah. ${ }^{30}$ PAS melibatkan diri

${ }^{30}$ Ibrahim Abu Bakar, "Perbandingan Pemikiran Politik Agama PAS dan UMNO", dalam Wan Hasyim Wan Teh, UMNO dalam Arus Perdana Politik Kebangsaan, (Kuala Lumpur: Mahir, 1997), 107. dalam politik demokrasi berparlemen di Malaysia, dengan cara mengikuti pemilu pertama tahun $1957 \mathrm{M}$. setelah terpilihnya Anggota parlemen PAS dan Dewan Undangan Negeri (anggota parlemen utusan Negara bagian), mereka berusaha membuat rancangan perbaikan UndangUndang; bentuk pemerintahan; dan sistem ekonomi demi membela kepentingan rakyat berdasarkan Islam. ${ }^{31}$

Di era tahun $70-80$ an PAS tampil dengan merubah haluan dengan mengedepankan kepemimpinan Ulama. Sehingga pada masa itu tokoh-tokoh yang mewakili parlemen dan pejabat setingkat Gubernur di negeri Bagian Kelantan adalah mereka yang berbasis lulusan pendidikan Timur Tengah. Mereka melakukan perubahan Perlembagaan PAS (AD), yaitu setelah terjadinya suksesi kepemimpinan tertinggi PAS dari DR. Mohd Asri Muda kepada Datok Yusuf Rawa yang lebih dikenal

31 Menteri Pendaftar Pertubuhan Malaysia, (Perlembagaan PAS), Pasal 6 ayat 5 . 
dengan keulamaanya. Perubahan itu mulai dilakukan pada saat diadakan Muktamar Agung PAS yang ke 28 tahun 1982. Kemudian tahun 1987 ditetapkan hasil perubahannya meliputi Pembentukan Majlis Syura Ulama yang beranggotakan 12 orang aktivis PAS. Mereka terdiri dari 4 orang pengurus PAS pusat; 4 orang pengurus Dewan Ulama PAS pusat; 4 orang lagi dipilih dan dilantik oleh Majlis Syura Ulama32. Majlis Syura Ulama ini berfungsi mirip dalam pemerintahan Islam yang dikenal dengan ahl al-halli wa al-aqd. Karena majlis ini berfungsi untuk memilih dan melantik pimpinan tertinggi pemerintahan dan membuat UndangUndang.

\section{Penerapan Syariat Islam di}

\section{Kelantan}

Berdasarkan Anggaran Dasar (AD) PAS, pasal 31987 yang dengan jelas meletakkan dasar partai untuk memperjuangkan Islam, yakni memperjuangkan terwujudnya di dalam Negara Malaysia,

32 Halim Mahmood, Asri Muda Dalam Dilema, (Kuala Lumpur :Hafar Enterprise, 1986), 19. pemerintahan yang terlaksana di dalamnya nilai-nilai hidup Islam dan hukum-hukumnya untuk menggapai keridhaan Allah. Kemudian Manifesto Pemilu Partai PAS di Negeri Kelantan dengan jelas menggariskan hasrat melaksanakan sistem perundangan berdasarkan AlQur'an, Hadis, Ijma', Ulama, dan Qiyas ${ }^{33}$. Perjuangan PAS dari aspek sejarah telah tampak bahwa, Kekuasaan partai PAS di Kelantan begitu lama, yaitu pada periode tahun 1959-1978, kemudian dilanjutkan pada tahun 1990 hingga sekarang, menjadikan hegemoni politik PAS di Kelantan begitu kuat. eksekutif dan legislatif sejak lama dikuasai dan dikontrol oleh PAS sehingga kekuatan politik lain sulit menguasai negeri Kelantan. Gerakan struktural yang mengandalkan kekuatan birokrasi pun begitu kukuh mempertahankan perjuangan 
pemberlakuan hukum jinayah di negeri Kelantan. ${ }^{34}$

Gerakan penerapan syariat Islam di negeri Kelantan terjadi perkembangan yang menarik setelah PAS di bahwah kepemimpinan Menteri Besar Datok Nik Abdul Aziz Nikmat sejak tahun 1990, Nampak sinergi antara partai PAS dan pemerintah mampu membuat berbagai kebijakan yang mampu menampung aspirasi Umat Islam. Pada awal kepemimpinannya, Pemerintah Kelantan memindahkan rekening bank dari bank konvensional ke bank Islam, memberantas tempat-tempat maksiat dan perjudian, penjualan minuman keras diatur secara ketat (perda), yang hanya diperuntukkan bagi nonMuslim, menertibkan tempat hiburan dan salon yang mengarah pada praktek seksual; SPA dan melarang pelestarian tradisi budaya Makyong dan Menora yang mengandung unsur sinkretisme; menghalangi segala bentuk iklan yang menampilkan

34 Rossem, 20 Tahun Menguak Gelombang (Selangor: SAR Publication and Distribution, 2011), 2. gambar-gambar wanita, dan mengatur berbagai tempat pangkas rambut yang selama ini diduga keras sebagai tempat pelacuran dan minum-minuman keras. ${ }^{35}$

Pada tahun 1993 pemerintahan Kelantan mengesahkan Enakmen Jenayah Syariah II Kelantan dimaksudkan untuk menggantikan Enakmen Kanun Jenayah Syariah 1985 karena undang-undang jinayah yang dilaksanakan di Malaysia pada umumnya dan Kelantan pada khususnya adalah undang-undang ciptaan manusia (al-ahkam al-wadiyah) dan merupakan warisan penjajah Inggris. Kondisi ini berbeda dengan masa sebelum dijajah, kesultanan di semenanjung Malaya dapat melaksanakan Undang-undang Islam secara keseluruhan. Usaha pengesahan ini dilakukan untuk mengembalikan undang-undang Islam agar dapat dilaksanakan di

35 Mazlan Jusoh dan Wan Nik Wan Yussof, Kelantan 20 Tahun di Bawah Teraju Ulama: Catatan Perkembangan Pentadbiran Kerajaan Negeri Kelantan selama 2 Dekade dalam 20 Tahun Pentadbiran Membangun Bersama Islam Kerajaan Kelantan, 36-41. 
Kelantan ${ }^{36}$ Pengundangan Enakmen

Jenayah Syariah di Kelantan 1993 sesuai dengan komitmen politik PAS untuk mengimplementasikan syariat Islam sebagai sistem hukum Malaysia, baik di level pemerintah federal pusat maupun negara bagian ${ }^{37}$. PAS dengan lantang meminta hukum syariah menggantikan sistem hukum Malaysia. PAS pun berjuang memberlakukan hukum jinayah dalam Enakmen Kanun Jenayah Syariah1993 meski mendapatkan tantangan dari pemerintah federal.

Enakmen Jenayah Syariah II 1993 di Kelantan dalam prakteknya, tidak dapat diimplementasikan karena ditolak oleh Pemerintah Federal Kuala Lumpur. Argumen yang dibangun Pemerintah Federal adalah karena Enakmen Kanun Jenayah Syariah itu bertentangan dengan Konstitusi Federal dan Akta

36 Tim Penyelidik, Program PAS Negeri Kelantan 1990 (Kota Bharu: Badan Perlindungan Negeri Kelantan, 2000), 13.

37 Zainah Anwar, Kebangkitan Islam di Malaysia (Jakarta: LP3ES, 1990), 2.
Mahkamah Syariah tahun $1984^{38}$. Jika Enakmen Jenayah ingin diberlakukan di Kelantan, maka Konstitusi Malaysia harus terlebih dahulu diamandemen dan Akta Mahkamah Syariah 1984 direvisi sehingga memungkinkan penerapan hukuman hudud dan qishas di Kelantan. Para politisi PAS sebenarnya telah menyadari sulitnya melakukan amandemen konstitusi, tetapi komitmen untuk memberlakukan syariat Islam tetap dijalankan, meski tidak disetujui oleh Pemerintah Federal UMNO Malaysia. Menurut analisis para pakar, yang berkembang di Malaysia menyebutkan bahwa formalisasi hukum jinayah di Kelantan dalam bentuk Enakmen Kanun Jenayah merupakan praktek politisasi PAS dalam menarik simpati masyarakat Muslim. Sedangkan MB. Hooker dan Virginia Hooker menyebut Enakmen Kanun Jenayah Syariah sangat penting nilainya bagi PAS sebagai

38 Pasal 4 ayat 1 dan Pasal 75 Perlembagaan Persekutuan (Konstitusi Malaysia). Lihat Perlembagaan Persekutuan, (Selangor: Internatinal Law Book Services, 2009). 
simbol komitmen PAS terhadap pemberlakuan syariat Islam $^{39}$. Ini juga menegaskan kepada publik bahwa PAS merupakan partai yang lebih islami daripada UMNO. Di sisi lain pemberlakuan syariat Islam sebenarnya ingin mengembalikan otoritas ulama yang telah lama digantikan oleh otoritas kekuasaan pemerintah.

\section{SIMPULAN}

Dari uraian di atas dapat diambil beberapa kesimpulan bahwa PAS memandang bahwa Islam adalah agama yang sempurna dan lengkap mencakup semua aspek kehidupan manusia termasuk di dalamnya mengurusi masalah kenegaraan. Negara Islam yang dicita-citakan PAS adalah pemerintahan Islam yang dibentuk atas dasar kedaulatan hukum Allah; ditegakkan atas dasar kekuasaan ummah; dasar keadilan, karena keadilan merupakan prinsip penting

39 M.B. Hooker ,"Southeast Asian Shari'ahs", dalam Studia Islamika, Volume 20 Nomor 2 (2013), 209. untuk kesejahteraan rakyat; sistem syura; dan pemerintah bertanggungjawab penuh atas rakyat Allah.

Agenda awal yang diperjuangkan PAS adalah menolak keberadaan nasionalisme melayu UMNO karena tidak dapat menempatkan Islam sebagai dasar Negara dan Islam hanya ditempatkan dalam salah satu bagian dan pelengkap saja; melaksanakan Hukum (Hudud) mencuri, zina, minum-minuman keras dan khalwat; Qishas dan Ta'zir; dan memperjelas peran wanita dalam politik dan sektor publik lain. Penerapan hukum Islam di Kelantan didasarkan pada Enakmen Jenayah Syariah Kelantan 1993 tentang hukum hudud, Qishas dan Tazir (pelanggaran asusila) dalam prakteknya, tidak dapat diimplementasikan karena ditolak oleh Pemerintah Federal Kuala Lumpur Malaysia. Argumen yang dibangun Pemerintah Federal adalah karena Enakmen Kanun Jenayah Syariah itu bertentangan dengan Konstitusi dan Akta Mahkamah 
Syariah tahun $1984^{40}$. Jika Enakmen

Jenayah ingin diberlakukan di

Kelantan, maka Konstitusi Malaysia

harus terlebih dahulu diamandemen

dan Akta Mahkamah Syariah 1984

direvisi sehingga memungkinkan

penerapan hukuman hudud dan qishas

di Kelantan.

Peraturan Daerah (perda)

syariah di Kelantan telah

diberlakukan seperti pelarangan

pelacuran di berbagai tempat hotel, panti pijat; dan tempat terselubung lain; pelarangan izin operasional diskotik; pelarangan penjualan minum-minuman keras di toko-toko, hotel maupun gerai besar dan kecil; pelarang izin operasional SPA dan panti pijat; pelarangan reklame maupun iklan yang menampilkan gambar perempuan.

40 Pasal 4 ayat 1 dan Pasal 75 Perlembagaan Persekutuan (Konstitusi Malaysia). Lihat Perlembagaan Persekutuan, (Selangor: Internatinal Law Book Services, 2009). 
DAFTAR PUSTAKA

Abdullah, Abdurrahman $\mathrm{H}$, Pemikiran Politik Islam di Malaysia, Sejarah dan Aliran, Jakarta: Gema Insani Press. 2007

Abdurrahman, Dudung, Metode Penelitian Sejarah, Jakarta: Wacana Ilmu, 1999

Ahmad, Ibrahim, Konflik UMNOPAS dalam Isu Islamisasi, Selangor: IBS Printed, 2003

Ahmad, Ibrahim, Pendirian PAS Mengenai Hudud, Ketua Penerangan PAS: 2011

Ahmad, Nakha'ie Haji, Konsep Negara Islam dan Matlamatnya, Kuala Lumpur: Syarikat Al-Muslimah, 2004

Andaya BW \& Andaya LY, A History of Malaysia, London: Macmillan Press, 1992

Awang, Hadi, Konsep Negara Islam dan Matlamatnya, Kuala Lumpur: Syarikat Al-Muslimah, 1998

Azam, Ahmad, Merdeka Dengan Perlembagaan, Penang: Pustaka Semenanjung, 1995

Azra, Azyumardi, Perspektif Islam di Asia Tenggara, Jakarta: Yayasan Obor, 1994
Efendi, Bakhtiar, Islam dan Negara; Transformasi Pemikiran dan Praktek Politik Islam di Indonesia, Jakarta: Paramadina, 2002

F. Soltau, Roger, An Introduction to Politics, London : Longmans, 1982

Funston, John, (edt.) Government and Politicsin Southest Asia, Singapure: ISEAS, 2001

Funston, John, Malay Politics In Malaysia : A study of The UMNO and PAS, Kuala Lumpur: Dinamika Kreatif SDN BHD, 1997

Ibrahim, Syafei, The Islamic Party of Malaysia Its Formatif Stages and Ideology, Kuala Lumpur: University Of Malaya, 1991

Imarah, Muhammad, Al-Islam wa alSulthanah al-Diniyyah, Kairo: Daarul Tsaqafah Jadidah, 1980

Izzat, Hibbah Rauf, Wanita dan Politik dalam Pandangan Islam, Bandung: Remaja Rosda karya, 2005

Jusuh, Abdullah, Pengenalan Tamadun Islam di Malaysia, Kuala Lumpur: dewan Bahasa dan Pustaka Kementerian Pendidikan Malaysia. 1992

Khamami, Pemberlakuan Hukum Jinayah di Aceh dan Kelantan, Jakarta: LSIP, 2014 
M.B. Hooker ,"Southeast Asian

Shari'ahs", dalam Studia

Islamika, Volume 20 Nomor 2 (2013)

Mauzy, and R.S. Milne, Politics and Government in Malaysia, Boston: Houghton Miflin, 1976

Mulyana, Dedi, Metode Penelitian Kualitatif, Bandung: Remaja Rosda Karya, 2002

Muzaffar, Candra, Islamic Resurgence In Malaysia, Petaling Jaya: Fajar Bakti. 1987

Negara, Ahmad Mansur Surya, Api Sejarah, Bandung: Salamadani, 2010

Pusat Penyelidikan PAS, Seri Sejarah Perjuangan Ummah PAS Dalam Arus Perjuangan Kemerdekaan, Selangor: Angkatan Edaran SDN BHD, 2000

Syadzali, Munawir, Islam dan Tata Negara: Ajaran, Sejarah dan Pemikiran, Jakarta: Universitas Indonesia Press, 2004

Yatim, Badri, Historiografi Islam, Jakarta: Logos, 1997 